\title{
REJUVINASI AKAR PADA TANAMAN JERUK TUA
}

Oleh:

\section{DAMANHURI *)}

\begin{abstract}
ABSTRAK
Tanaman jeruk dapat mencapai umur produktif lebih dari 10 tahun, tetapi pada kenyataannya umur produktif tanaman kurang dari 10 tahun, bahkan sebagian besar tanaman jeruj di Jember hanya mencapai umur 6 sampai 7 tahun. Penyebab utama singkatnya umur produktif tanaman karena rapatnya populasi tanaman, sehingga terjadinya overlapping akar tanaman dalam waktu singkat. Dengan demikian akan terjadi kompetisi nutrisi antar tanaman. Untuk itu, perlu diupayakan pertumbuhanakarbaru(akarrejuvinasi) yang dapat menunjang pertumbuhan dan produksi tanaman sehingga umur produktif tanaman dapat diperpanjang. Penelitian ini bertujuan untuk menumbuhkan akar baru pada tanaman jeruk tua. Dan dilakukan dengan menggunakan Rancangan Acak Lengkap dengan dua faktor, yaitu perlakuan keratin leher akar dan aplikasi zat perangsang tumbuh akar yang terdiri dari ZPT Rootone-F dan ZPT-Biorin. Hasil penelitian memperlihatkan bahwa keratin leher akar dapat merangsang pembentukan akar baru,sedangkan perlakuan zat pengatur tumbuh secara tunggal tidak dapat merangsang pembentukan akar. Disamping itu hasil penelitian memperlihatkan bahwa jumlah akar terbanyak karena pengaruh keratin leher akar sebanyak 56,45/buah. Adapun akar terpanjang diperoleh pada perlakuan keratin akar dan Biorin dengan rata-rata panjangakar 7,65 cm. Keratan leher akar yang dikombinasi dengan aplikasi zat pengatur tumbuh biorin dapat dipergunakan untuk merangsang pembentukan akar baru pada kebun jeruk yang telah melewati umur produksi (kebun tua)
\end{abstract}

Kata kunci : Rejuvinasi

\section{PENDAHULUAN}

\section{LatarBelakang}

Secara alamiah tanaman jeruk siam merupakan tanaman tahunan yang dapat mencapai umur produktif sampai 20 tahun bahkan apabila dipelihara dengan baik dapat mencapai lebih dari umur tersebut. Pemeliharan yang penting agar tanaman berumur panjang adalah jarak tanamlebar ( 5 x 6 meter) dengan ketersediaan zona perakaran yang cukup, ketersediaan unsure hara dan air yang memadai,dan disertai dengan kecukupan air serta drainase yang baik sesuai dengan pertumbuhan tanaman.

Kondisi spesifik jeruk siam di Jemberberadapada areal bekas sawah yang ditanam dengan jarak tanaman rapat (sekitar 3,5 $\mathrm{x}$ 4 meter) dengan populasi sekitar 700 tanaman/hektar. Guna mencegah terjadinya penggenangan, maka dibuat saluran pembuangan/penuntas dengan sistem 2 barisan tanaman 1 saluran penuntas.

Jarak tanam sempit yang disertai dengan adanya saluran pembuangan, berakibat pada terbatasnya zona perakaran tanaman. Dengan asumsi pertumbuhan akar kesamping $0,5 \mathrm{~m} /$ tahun, maka hanya dalam waktu 5 -6 tahun akar jeruk tersebut telah saling bersentuhan atau telah sampai pada saluran penuntas.Perakaran tanaman yang telah berumur lebih dari 10 tahun telah tumbuh dan berkembang sangat jauh dari batang utama sehingga menyulitkan dalam pemberian pupuk. Dampak langsung adalah umur produktif tanaman yang menguntungkan secara ekonomis hanya berkisar sekitar 10 tahun. Lebih dari umur tersebut tanaman masih berproduksi tetapi kurang menguntungkan secara ekonomi. Tanaman jeruk yang berumur diatas 10 tahun sudah harus dibongkar karena kurang menguntungkan bagi petani. 
Pembongkaran jeruk berumur 10 tahun di Jember dapat dilihat dari penyempitan luas lahan. Luas lahan jeruk siam tahun 2005 tercatat sekitar 7000 ha. Pada tahun 2009 hanya tersisa sekitar 5000 ha (Diperta Jember, 2009) . Penurunan luas lahan tersebut terjadi karena umur tanaman sebagian besar telah mencapai lebih dari 10 tahun.

Umur tanaman yang sangat pendek tersebut terjadi karena tanaman jeruk menjadi kurang efektif dalam menyerap unsur hara sebagai akibat pertumbuhan akar serabut yang telah melebar sangat luas, bahkan terganggu karena terjadi overlapping dan sebagian besar telah sampai pada saluran drainase (saluran penuntas). Sistem budidaya jeruk pada areal bekas tanaman padi (persawahan) mempunyai kendala terbesar pada masalah drainase. Guna mencegah penggenangan dibuat saluran penuntas sejajar barisan dengan sistem 2 barisan tanaman 1 saluran penuntas. Ukuran saluran penuntas adalah: dalam $50-75$ $\mathrm{cm}$, lebar $50 \mathrm{~cm}$ dengan panjang disesuaikan bentuk lahan. Dengan jarak tanam hanya 3,5 x 4 $\mathrm{m}$, maka adanya saluran penuntas tersebut telah mempersempit zona perakaran tanaman sehingga umur produktif hanya sekitar 10 tahun

Upaya untuk mengatasi agar akar tanaman tidak tergenang, dilakukan dengan cara menggali saluran penuntas (memperdalam saluran penuntas) dimana tanah hasil galian disebarkan diatas permukaan tanah disekitar tanaman. Tanah galian tersebut sebenarnya sangat potencial sebagai zona perakaran baru bagi tanaman. Oleh karena itu,rangsangan perakaran pada leher akar yang disertai dengan pangkasanakar/pemotongan akar dapat mengatur akar serabut yang terbentuk dan dapat meningkatkan efektifit as pemupukan sehingga dapat meningkatkan produksi tanaman. Disamping itu, akan sangat efektif dalam memperpanjang umur produksi tanaman karena dapat memanfaatkan zona perakaran baru diatas permukaan tanah lama.

\section{TujuanKhusus}

Penelitian dengan judul rejuvinasi akar pada tanaman tua untuk memperpanjang umur produksi tanaman jeruk ini bertujuan untuk :

a. Untukmendapatkanpertumbuhanakarbaru

b. Untukmemperpanjangumurproduksitanaman

\section{KeutamaanPenelitian}

Pembongkaran tanaman jeruk pada umur

10 tahun merupakan tindakan yang sangat merugikan bagi petani. Seharusnya umur ekonomis tanaman jeruk yang merupakan tanaman tahunan dapat mencapai 20 tahun. Analisis ekonomi dengan memperhatikan produksi buah awal pada tahun ke 2-3 dengan tingkat produksi hanya sekitar $10-20 \mathrm{~kg} /$ pohon dan terus meningkat sampai puncaknya pada umur 5- 8 tahun dan kemudian menurun pada umur lebih dari 10 tahun ternyata sangat merugikan petani. Pembongkaran tanaman pada umur 10 tahun, sangat merugikan petani karena beberapa hal yaitu: 1) Produksi buah jeruk baru dimulai tahun ke 2 - 3 . 2) Produksi awal sangat rendah yaitu hanya $10-$ $20 \mathrm{~kg} /$ pohon. 3) Masa produksi puncak cukup singkat dan hanya $2-3$ tahun. Dengan pertimbangan tersebut apabila dilakukan pembongkaran pada tahun ke 10, maka setiap usaha tani jeruk akan selalu kurang menguntungkan. Oleh karena itu perlu dilakukan cara lain yang sesuai dengan permasalahan yang terjadi dilapangan. Salah satu caranya adalah dengan mengembangkan teknologi Cangkok Batang pada leher akar untuk membentuk akar baru (akarrejuvinasi).

Disamping kelemahan diatas, jeruk Siam memang memiliki beberapa kelemahan lain yaitu: (1) warna kulit buah hijau kekuningan (warna kuning yang kurang cerah); serta (2) rasa buah yang kurang manis dan seringkali meninggalkan rasa getir di lidah. Oleh karena itu masalah perbaikan kualitas buah menjadi sangatpenting danmendesakuntuk dikaji lebih jauh mengingat mayoritas pertanaman jeruk di Indonesia adalah jeruk siam. Strategi pengembangan jeruk siam di Indonesia selayaknya difokuskan pada pemantapan areal sentra produksi yang telah ada mengingat ketersediaan lahan yang cenderung menyempit, upaya dapat dilakukan dengan lebih mengoptimalkan teknologi pemeliharaan tanaman, khususnya yang terkait dengan pemupukan penentu kualitas buah pada kebun tua dan penanganan buah sebelum panen sehinggga akan diperoleh buah dengan penampilan menarik sesuai selera konsumen.

Kadar PTT buah jeruk dan kadar asam askorbat berkorelasi positip dengan unsur $\mathrm{Ca}$ tanaman. Semakin tinggi kandungan $\mathrm{Ca}$ tanaman maka kadar PTT dan kandungan asam askorbat buah semakin meningkat. Berdasarkan hasil penelitian pemupukan di lahan pasang surut memperlihatkan bahwa unsur $\mathrm{Ca}$ dan $\mathrm{Mg}$ berkorelasi positif dan sangat nyata pengaruhnya terhadap kadar padatan terlarut total (PTT) dan nisbah kadar PTT/ kadar asam. Oleh karena itu terlihat bahwa upaya untuk mengoptimalkan status nutrisi tanaman melalui pemupukan serta optimalisasi status nutrisi di dalam jaringan tanaman perlu diupayakan agar terjadi secara optimal yaitu dengan cara mengatur kadar nutrisi 
$\mathrm{Ca}, \mathrm{Mg}$ dan $\mathrm{K}$ pemupukan terutama pada periode perkembangan buah.

Penampilan buah yang menarik dipengaruhi oleh keseragaman ukuran, warna kulit buah serta bersih dari bercak akibat OPT penyebab burik kusam. Penampilan warna jeruk siem seringkali dominan hijau, hal ini disebabkan karena saat panen yang kurang tepat (belum mencapai masak fisiologis), juga dipengaruhi karena belum berkembangnya pigmen karotenoid yang belum optimal. Kondisi ini disebabkan karena kondisi agroklimat, terutama suhu di dataran rendah yang kurang mampu mendorong terbentuknya pigmen karotenoid (warna kuning) pada kulit buah. Oleh karena itu, perlu pengembangan teknologi untuk dapat lebih mengoptimalkan pembentukan pigmen pada jeruk siam untuk memperoleh penampilan yang lebih menarik, yaitu melalui manipulasi sinar yang dapat merangsang pembentukan pigmen karotenoid pada buah. Studi radiasi matahari melalui pembungkusan buah dengan anekawarna dapat memberikan hasil perbaikan penampilan kulit buah sesuai selera konsumen.

\section{METODE PENELITIAN HASIL DAN PEMBAHASAN}

Perlakuan rejuvinasi akar dilakukan dengan membuat keratan pada leher akar sebagaimana tertera dalam gambar 1 berikut.
Penelitian dilaksanakan di sentra produksi jeruk siam, yaitu di Desa Sukoreno, Kecamatan Umbulsari, Kabupaten Jember, pada jenis tanah Asosiasi Glei humus rendah dan Aluvial Kelabu, dengan bahan induk endapan liat. Ketinggian tempat $17 \mathrm{~m}$ di atas permukaan laut, dengan suhu udara rata-rata berkisar antara $23-32^{\circ} \mathrm{C}$, dengan curah hujan rata-rata $1600-2400 \mathrm{~mm} / \mathrm{th}$. Waktu penelitian mulai bulan April 2011 sampai dengan bulan Januari 2012.

Penentuan lokasi penelitian dilakukan dengan menentukan petak-petak yang dapat mewakili, yaitu kebun yang berumur kurang dari 10 tahun tetapi telah menunjukkan kemunduran produksi sampai hanya mencapai $50 \%$ dari potensi produksi yang seharusnya. Pohon yang memiliki diamter batang yang sama diambil sebagai unit penelitian, yaitu sebanyak 18 tanaman, dengan 3 perlakuan dan diulang 6 kali. Adapun perlakuan terdiri dari 1) Keratan leher akar (K) dan 2)

Pemberian ZPT (Z) untuk merangsang pertumbuhan akar baru yang terdiri dari :Z1 : dengan pemberian ZPT Rootone - F, Z2 : dengan pemberian ZPT Biorin.Analisis data dilakukan dengan menggunakan uji varian dan dilanjutkan dengan uji LSD 5\%, dengan menggunakan bantuan program SPSS versi 16.

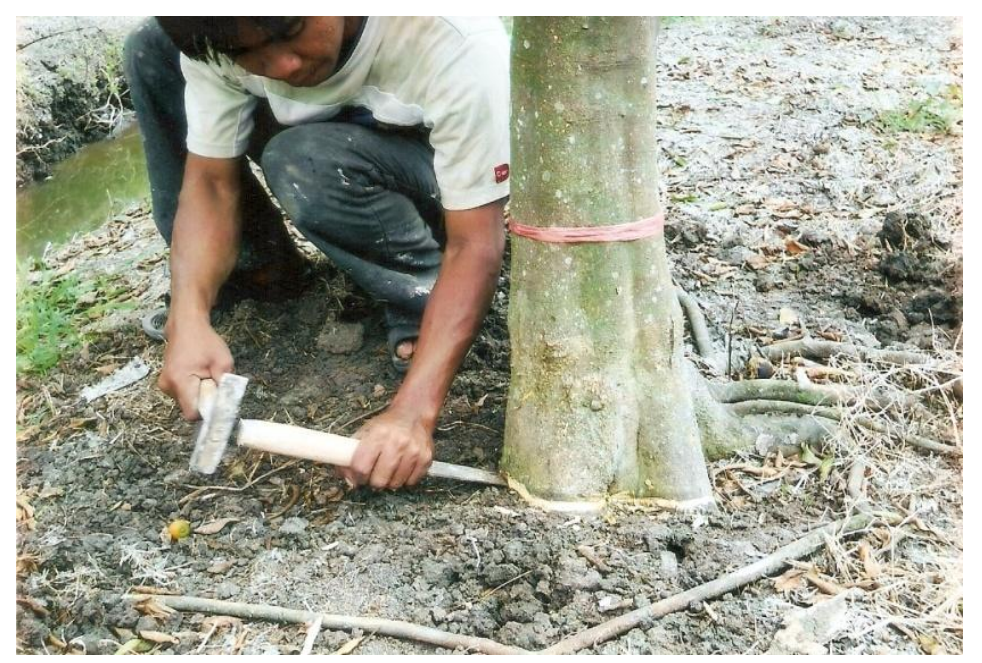

Gambar 1. Rejuvinasi akar dilakukan dengan pengkeratan leher akar tanaman.

Terlihat dalam gambar 1 bahwa pengkeratan leher akar dilakukan dengan menggunakan tatah karena tebalnya kulit batang sehingga akan diperoleh keratan yang sempurna. Perlakuan ini dilakukan dengan hati-hati agar tidak sampai melukai batang utama tanaman. Selanjutnya hasil keratan diberikan perlakuan untuk meransang pertumbuhan akar baru dengan mengoleskan ZPT berupa Rootone-F serta Biorin. Rootone-F digunakan karena bahan ini merupakan bahan yang 
sering digunakan dengan tujuan untuk merangsang akar baru, karena adanya auxin sebagai kandungan utama pada bahan ini. Sedangkan Biorin digunakan karena adanya senyawa kompleks yang ada pada biorin, terutama adanya ZPT perangsang akar yang disertai unsur N, P serta K. Diharapkan adanya subtitusi nutrisi akan membantu percepatan pertumbuhan akar baru. Perlakuan dilakukan dengan mengoleskan masing-masing sesuai dengan perlakuan seperti nampak pada gambar 2 .

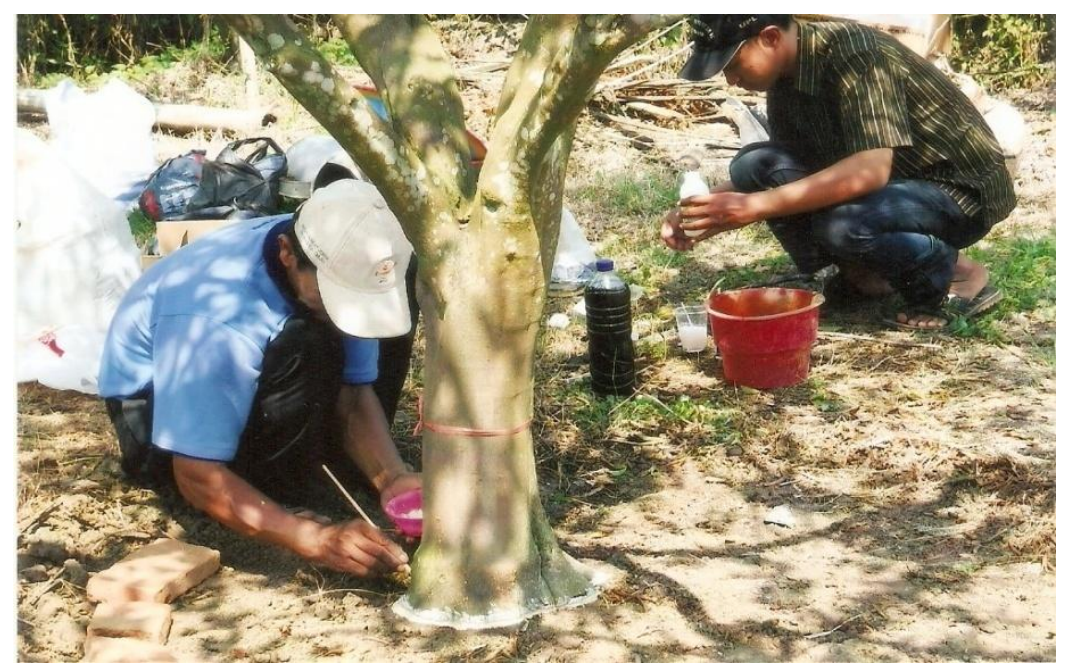

Gambar 2. Perlakuan pemberian ZPT Rootone-F serta Biorin dengan Teknik Pengolesan.

Akar yang terbentuk pada perlakuan dapat tumbuh dengan baik seperti tertera pada gambar berikut.

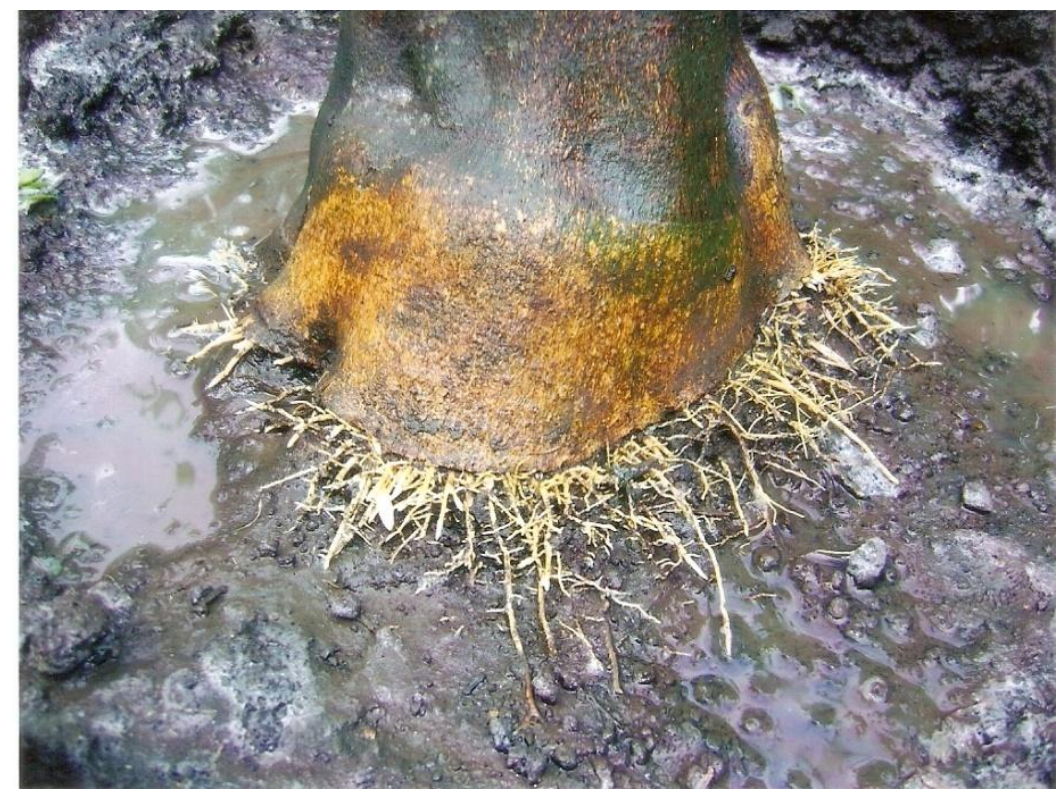

Gambar 3 . Pertumbuhan Akar Baru Hasil Rejuvinasi Akar

Pada gambar diatas menunjukkan adanya pertumbuhan akar baru hasil rejuvinasi. Selanjutnya,pengamatan dilakukan dengan cara menghitung jumlah akar dan panjang akar setiap 2 minggu sekali yang dilakukan selama 4 bulan. Hasil analisis jumlah akar dan panjang akar dapat dilihat pada Tabel 1 berikut ini. 
Tabel 1. Rata-ratajumlah dan panjang akar tanaman Jeruk Siam hasil rejuvinasi

\begin{tabular}{lll}
\hline Perlakuan & Jumlah Akar/Tanaman & Panjang Akar $(\mathrm{cm})$ \\
\hline Kerat Saja & $56,45 \pm 7,36 \mathrm{a}$ & $5,75 \pm 1,76 \mathrm{a}$ \\
\hline Kerat + Rootone-F & $54,80 \pm 4,09 \mathrm{ab}$ & $6,92 \pm 1,80 \mathrm{~b}$ \\
\hline Kerat + Biorin & $53,44 \pm 4,30 \mathrm{~b}$ & $7,65 \pm 2,23 \mathrm{~b}$ \\
\hline
\end{tabular}

Keterangan: Rerata yang diikuti dengan notasi yang sama pada kolom yang sama menunjukkan hasil yang tidak berbeda nyata pada LSD 5\%

Tabel 1 menunjukkan bahwa perlakuan zat pengatur tumbuh (ZPT) tidak menghasilkan rerata jumlah akar yang berbeda nyata.Meskipun demikian, dilihat dari jumlah akarnya, maka tampak perlakuan kerat menunjukkan jumlah akar terbanyak, yaitu 56,45 akar/tanaman. Adapun perlakuan ZPT mempengaruhi secara nyata terhadap panjang akar, meskipun perlakuan Kerat + Rootone-F dan Kerat + Biorin tidak menunjukkan hasil yang berbeda nyata. Akar yang terpanjang didapatkan pada perlakuan Kerat + Biorin, dengan rerata 7,65 $\pm 2,23 \mathrm{~cm}$. Oleh karena itu, dapat disimpulkan bahwa perlakuan Kerat Saja justru yang akan dipilih dalam aplikasi di lapang, karena hasil yang diharapkan justru hasil rejuvinasi dengan jumlah akar yang banyak tetapi tidak panjang, dengan harapan efektivitas serapan pupuk dapat ditingkatkan dan pertumbuhan sertap roduksi tanaman dapa tditingkatkan/diperpanjang.

\section{Jumlah Akar}

Hasil penelitian membuktikan bahwa perlakuan keratan leher akar dapat membentuk akar baru seperti yang tertera pada Gambar 4.Demikian pula pada gambar tersebut menunjukkan bahwa dengan penambahan ZPT dapat membantu menumbuhkan akar lebih awal dibandingkan dengan tanpa pemberian ZPT.Tampak pada pemberian Biorin akar mulai tumbuh pada minggu ke-3, sedangkan pada minggu ke-4 pemberian Rootone-F dapat membantu mempercepat tumbuhnya akar. Adapun pada minggu ke-5 pertumbuhan akar tanpa pemberian ZPT baru dimulai, meskipun dengan rata-rata jumlah akar lebih sedikit dibandingkan dengan perlakuan ZPT. Meskipun demikian, setelah dilakukan pengamatan mulai minggu ke-5 sampai minggu ke-8 justru perlakuan tanpa pemberian ZPT menunjukkan jumlah akar yang paling banyak, yaitu sebanyak 59,50 akar/tanaman pada minggu ke-8.

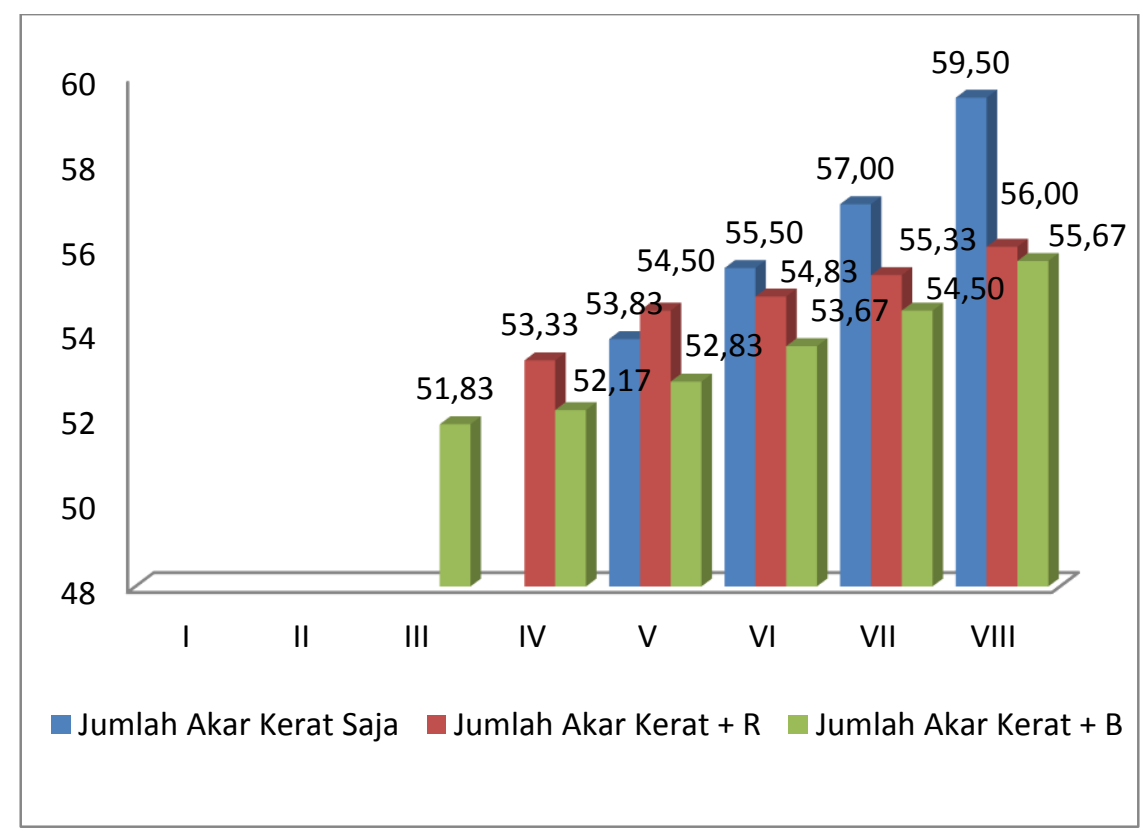

Gambar 4. Rata-rata Jumlah akar Hasil Rejuvinasi 


\section{Panjang Akar}

Hasil pengamatan perubahan panjang akar setiap 2 minggu disajikan dalam gambar berikut.

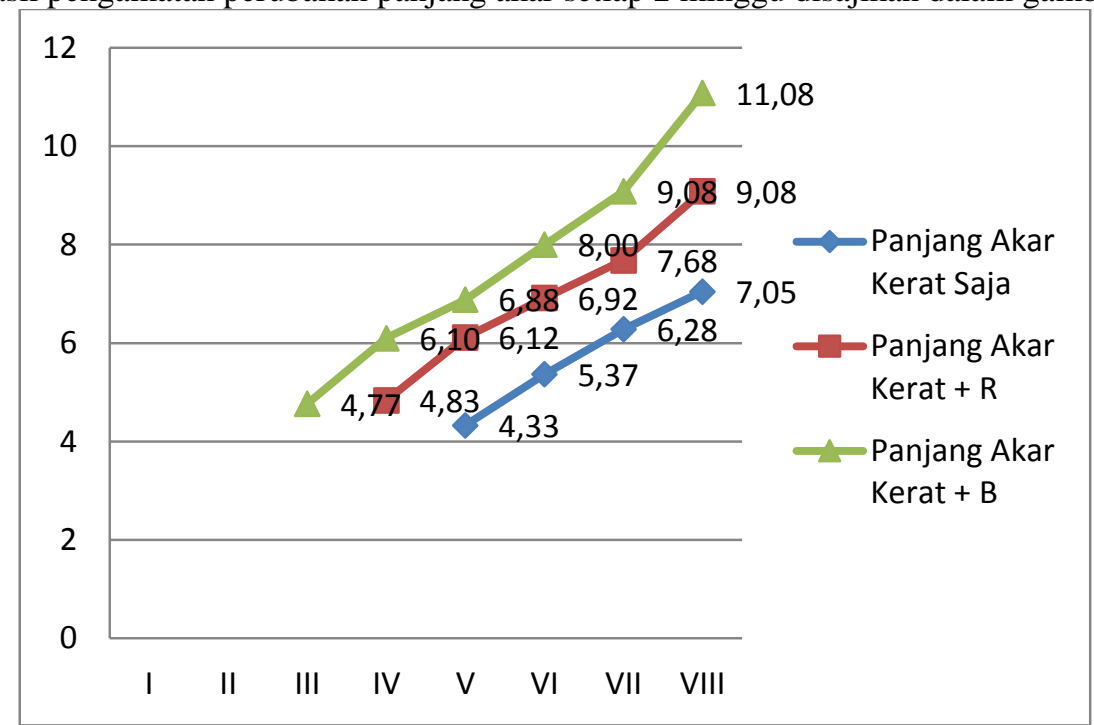

Gambar 5. Rata-Rata Panjang Akar Hasil Rejuvinasi

Hasil pengamatan panjang akar justru menunjukkan kecenderungan yang berbeda, meskipun dengan perlakuan ZPT jumlah akar lebih sedikit dibandingkan dengan tanpa perlakuan ZPT, tetapi justru diperoleh akar yang lebih panjang dengan menggunakan perlakuan ZPT (Gambar 5). Perbedaan panjang akar ini dapat dipahami bahwa jika dilakukan perangsangan akar maka akar yang terbentuk lebih cepat tetapi dengan jumlah akar paling sedikit, karena jumlah asimilat hasil fotosintesis justru terkonsentrasi pada pemanjangan akar, dan sebaliknya pada perlakuan tanpa ZPT meskipun pertumbuhan inisiasi akar agak terlambat tetapi jumlah akar yang terbentuk justru semakin banyak, karena hasil asimilat tidak terlalu terkuras untuk pemanjangan akar baru.Tampaknya justru perlakuan ini yang diharapkan dapat diplikasikan pada penerapan selanjutnya.

\section{KESIMPULAN}

Dari hasil penelitian didapatkan bahwa: 1) Rejuvinasi akar dapat dilakukan dengan perlakuan pengkeratan leher akar untuk perbaikan sistem perakaran kebun jeruk tua.2) Perlakuan Kerat leher akar tanpa ZPT menunjukkan jumlah akar terbanyak sebesar 56,45 akar/tanaman 3) Perlakuan Kerat dengan aplikasi ZPT Biorin meningkatkan panjang akar tanaman rata rata terpanjang 7,65 $\mathrm{cm}$. Berdasarkan pada hasil penelitian yang telah dilakukan maka dapat disarankan hal hal sebagai berikut : 1) Sebaiknya rejuvinasi akar dilakukan tanpa penambahan ZPT, baik Rootone-F maupunBiorin. 2) Perlu dilakukan penelitian lanjutan serupa pada tanaman produktif (kebun muda) untuk memperpanjang umur ekono misjeruk 


\section{DAFTAR PUSTAKA}

Achmadi, Annisa,W. Maf'tuah, E. 2007. Hubungan Sifat Kimia Tanah terhadap Kualitas Buah Jeruk di lahan Rawa Lebak. Dalam Prosiding Seminar Nasional Jeruk 2007 Yogyakarta 13-14 Juni 2007.

Ashari, S. 2004. Biologi Reproduksi Tanaman Buah-Buahan Komersial. Bayumedia. Malang.200p.

Buku Tahunan Hortikultura Tahun 2003 Seri Tanaman Buah. 2004. Departemen Pertanian Direktorat Jenderal Bina Produksi Hortikultura.

Damanhuri. 2004. Peningkatan Produksi Jeruk Melalui Pangkasan dan Pemupukan Berimbang. Makalah pada Pelatihan Penyuluh Agribisnis Jeruk Kabupaten Jember, Dinas Tanaman Pangan Kabupaten Jember 8 Agustus 2004.

Dimyati, A. 2007. Keragaan, Tantangan dan Kendala Serta Kebijakan Pengembangan Jeruk Siam. Semiloka Nasiona: Optimalisasi Pengelolaan Tantangan Jeruk Siem Sebagai Komoditas Unggulan Nasional. Jember 09 Juni 2007

Gardner.F.P.,Perace, R.B and Mitchell, R.L. 1985. Physiology of Crop Plants.Iowa State University. Press Ames

Jabri, M. 2006. Uji Tanah dan Analisis Daun untuk Budidaya Tanaman Jeruk. Prosiding Seminar Nasional Jeruk Tropika Indonesia, Batu 28-29 Juli 2005. Pusat Penelitian dan Pengembangan Hortikultura Badan Penelitian dan Pengembangan Pertanian

Jumberi, A., Maf'tuah, E., Annisa, W, 2006. Hubungan Sifat Kimia Tanah terhadap Kualitas Buah Jeruk di Lahan Rawa Pasang Surut. Jurnal Agrivita. Universitas Brawijaya Malang
Ladaniya, MS. 2008. Citrus Fruit, Biology, Technology and Evaluation. Academic Press.557p

Ohishi, H., Watanabe, J., and Kadoya, K. 1996. Effect of red light irradiation on skin coloration and carotenoid composation of Stored 'Miyauchi' iyo (Citrus iyo hort. Ex Tanaka) tangor fruit.Bull. Exp,FarmColl, Agric, Ehime-University, No 17.pp.33-37

Poerwanto, R.2004. Program Pengembangan Jeruk Siem Di Indonesia. Prosiding Seminr Jeruk Siem Nasional. Surabaya 1516 Juni. Pusat Penelitian dan Pengembangan Hortikultura Badan Penelitian danPengembangan Pertanian.

Rosenberg, N.J,1987. Microclimate: The Biological Environment. John Wiley \& Sons. New York.

Soelarso, B. 2007. Budidaya Jeruk Bebas Penyakit. Kanisius. Yogyakarta.97p.

Supriyanto, A; Dwiastuti, ME; Triwiratno, A; Endarto,O; Suhariyono. 2003. Panduan Teknis Pengelolaan Terpadu Kebun Jeruk Sehat Strategi Pengendalian Penyakit CVPD. Loka Penelitian Tanaman Jeruk dan Hortikultura Subtropik. Pusat Penelitian dan Pengembangan Hotikultura Badan Penelitian dan Pengembangan Pertanian Departemen Pertanian.

Suprijanto, A. 2007. Peningkatan Kualitas Buah Jeruk Keprok Siem dengan Teknik Budidaya yang Tepat. Prosiding Seminr Jeruk Siem Nasional. Surabaya 15-16 Juni. Pusat Penelitian dan Pengembangan Hortikultura Badan Penelitian dan Pengembangan Pertanian.

Winarno, M. 2004. Keunggulan dan Kelemahan Jeruk Siem di Indonesia. Prosiding Seminar Jeruk Siem Nasional. 15-16 Juni. Pusat Penelitian dan Pengembangan Hortikultura Badan Penelitian dan Pengembangan Pertanian. 
Jurnal Ilmiah INOVASI, Vol.13 No.2, Hal. 185-191, Mei-Agustus 2013, ISSN 1411-5549 